\title{
Association between smoking status and the parameters of vascular structure and function in adults: results from the EVIDENT study
}

\author{
Jose I Recio-Rodriguez ${ }^{*}$, Manuel A Gomez-Marcos', Maria C Patino Alonso², Carlos Martin-Cantera², \\ Elisa Ibañez-Jalon ${ }^{4}$, Amor Melguizo-Bejar ${ }^{5}$, Luis Garcia-Ortiz ${ }^{1}$ and on behalf of the EVIDENT Group
}

\begin{abstract}
Background: The present study analyses the relation between smoking status and the parameters used to assess vascular structure and function.

Methods: This cross-sectional, multi-centre study involved a random sample of 1553 participants from the EVIDENT study. Measurements: The smoking status, peripheral augmentation index and ankle-brachial index were measured in all participants. In a small subset of the main population (265 participants), the carotid intima-media thickness and pulse wave velocity were also measured.

Results: After controlling for the effect of age, sex and other risk factors, present smokers have higher values of carotid intima-media thickness $(p=0.011)$. Along the same lines, current smokers have higher values of pulse wave velocity and lower mean values of ankle-brachial index but without statistical significance in both cases.
\end{abstract}

Conclusions: Among the parameters of vascular structure and function analysed, only the IMT shows association with the smoking status, after adjusting for confounders.

Keywords: Smoking, Carotid intima-media thickness, Vascular stiffness

\section{Background}

A consistent relationship has been demonstrated between cigarette smoke exposure and the progression of carotid atherosclerosis [1], with a strong positive association with coronary artery calcium burden [2]. Smoking has been associated with increased arterial stiffness and central hemodynamic indices [3-6]. There is evidence that the ankle-brachial index inversely and linearly correlates with cigarette smoking $[7,8]$. Nevertheless, when evaluating vascular structure and function, every test has different accessibility and costs [9]. Several authors have proposed that the patient's age, sex, blood pressure and heart rate, and the presence of obesity, diabetes and vascular drugs, are the main determinants of the parameters that assess arterial stiffness and vascular function [10-13]. The aim of this study was to assess the relationship between smoking

\footnotetext{
* Correspondence: donrecio@gmail.com

${ }^{1}$ La Alamedilla Health Centre, Castilla y León Health Service-SACYL, redIAPP, IBSAL, Salamanca, Spain

Full list of author information is available at the end of the article
}

status and vascular structure and function in a random sample of the adult population from the EVIDENT study.

\section{Methods \\ Study design and population}

The EVIDENT study is a cross-sectional and multi-centre study of six patient groups distributed throughout Spain. Participants, aged $20-80$ years, were selected by stratified random sampling. The following exclusion criteria were applied: known coronary or cerebrovascular atherosclerotic disease, heart failure, moderate or severe chronic obstructive pulmonary disease, walking-limiting musculoskeletal disease, advanced respiratory, renal or hepatic disease, severe mental disease, treated oncological disease diagnosed in the past 5 years and terminal illness. The study was approved by an independent ethics committee from Salamanca University Hospital (Spain), and all participants provided written informed consent according to the general recommendations of the Declaration of Helsinki. The recruitment and data collection were conducted between

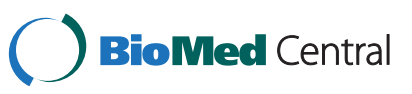

(C) 2013 Recio-Rodriguez et al.; licensee BioMed Central Ltd. This is an open access article distributed under the terms of the Creative Commons Attribution License (http://creativecommons.org/licenses/by/2.0), which permits unrestricted use, distribution, and reproduction in any medium, provided the original work is properly cited. 
2011 and 2012. A total of 1553 individuals were included in the study. The sample size calculation indicated that this number was sufficient to detect a difference of 5 units in the peripheral augmentation index between 3 smoking statuses (i.e., smoker, former smoker and non-smoker) in a two-sided test, assuming a common standard deviation (SD) of 21 units with a significance level of $95 \%$ and a power of $90 \%$. The IMT and PWV were measured in only 265 participants, but this number was sufficient to detect a $0.05 \mathrm{~mm}$ difference in the IMT between the 3 groups, assuming a SD of 0.1, a significance level of $95 \%$ and a power of $80 \%$. The findings presented in this manuscript are a subanalysis of the EVIDENT study, the main results of which were recently published [14].

\section{Variables and measurement instruments}

Smoking history was assessed by asking questions about the participant's smoking status. For the analyses, the participants were classified as non-smokers, former ( $>1$ year without smoking) or present smokers. Carotid ultrasonography to assess intima-media thickness of the common carotid artery (C-IMT) was performed with the Sonosite Micromax ultrasound device (Sonosite Inc., Bothell, Washington, USA) paired with a 5-10 MHz multifrequency high-resolution linear transducer. Sonocal software was used to perform automatic IMT measurements. Six measurements were performed on each carotid artery using average values (average IMT) and maximum values (maximum IMT) automatically calculated by the software. The measurements were taken following the recommendations of the Manheim Carotid Intima-Media Thickness Consensus [15]. Carotid-femoral pulse wave velocity (PWV) was estimated using the SphygmoCor System (AtCor Medical Pty Ltd., Head Office, West Ryde, Australia), according to the expert consensus document on arterial stiffness by Van Bortel et al. [16]. The central blood pressure and radial or peripheral augmentation index (PAIx) were measured with the Pulse Wave Application Software (A Pulse) (HealthSTATS International, Singapore) using tonometry to capture the radial pulse and to estimate the central blood pressure using a patented equation. The PAIx was calculated as follows: (second peak systolic blood pressure [SBP2] - diastolic blood pressure [DBP])/ (first peak SBP - DBP) $\times 100(\%)$. The PAIx was standardised to a heart rate of $75 \mathrm{bpm}$. The ankle-brachial index (ABI) was measured using a portable WatchBP Office ABI (Microlife AG Swiss Corporation). The ABI was calculated automatically dividing the higher of the two ankle systolic pressures by the highest measurement of the two systolic pressures in the arm [17]. All measurements (IMT, PWV, PAIx75 and ABI) were performed in the morning. Smoking was not allowed within the $3 \mathrm{~h}$ prior to the measurements. Further details on the EVIDENT study design have been published elsewhere [18].

\section{Statistical analysis}

Statistical normality was checked using the KolmogorovSmirnov test. Normally distributed continuous variables were expressed as the mean \pm standard deviation, while non-normally distributed variables were presented as median and 75-25th percentile. Frequency distribution was used for the categorical variables. The difference in means in continuous variables between the smoking categories was analysed using a one-way analysis of variance for independent samples and the post-hoc Scheffé contrast, with alpha $<0.05$ and the Kruskal-Wallis test when the variables were not normal. Chi-squared tests were used to compare the differences in categorical variables.

Age, sex, blood pressure, heart rate, and the presence of obesity, diabetes and vascular drugs have shown to affect the PWV, IMT or augmentation index values. Therefore, it is necessary to control the effect of these variables in the relationship between smoking status and the parameters of vascular structure and function. To analyse the relationship between the vascular structure and function (IMT, PAIx75, PWV or ABI) and smoking status (non-smoker $=0$, present smoker $=1$, former smoker $=2$ ), a general linear model (GLM) analysis was performed, including age, sex, systolic blood pressure, heart rate, body mass index, HDL cholesterol, diabetes and the presence of antihypertensive, antidiabetic and lipid-lowering drugs as the adjustment variables. The non-normal variables were modelled as continuous variables with log transformation to achieve normality in the multivariate analysis. Data were analysed using the SPSS version 18.0 statistical package (SPSS Inc., Chicago, Illinois, USA), and $\mathrm{p}<0.05$ was considered to be statistically significant.

\section{Results}

Table 1 shows the clinic characteristics of each group according to its smoking status. Current smokers are younger and have the lowest prevalence of hypertension, obesity and dyslipidemia. PWV, IMT and ABI are lower in present smokers, while PAIx75 are higher in these individuals. An analysis of the 265 individuals for whom the IMT and PWV were performed is shown in Additional file 1: Table S1. The results showed that the demographic and biological characteristics, according to smoking status, were similar to the overall analysed sample. The mean package year in the present smokers was $16.78 \pm 16.31$, and the average smoking history was $30.39 \pm 12.57$ years. In an age-adjusted correlation, we found a positive correlation between the package years and the PAIx75 $(\mathrm{r}=0.332, \mathrm{p}=0.015)$ and a negative correlation with the ABI $(r=-289 ; p=0.036)$. The PWV and IMT showed no significant correlations.

Table 2 shows the IMT, PWV, PAIx75 and ABI values according to patient sex; the presence of diabetes, antihypertensive, antidiabetic and lipid-lowering drugs. IMT 
Table 1 Characteristics of patients by smoking status

\begin{tabular}{|c|c|c|c|c|}
\hline & Nonsmokers $(n=747)$ & Former smokers $(n=469)$ & Present smokers $(n=337)$ & $\mathrm{p}$ value \\
\hline Age (years)* $¥$ & $56.14(65.09-43.64)$ & $55.69(64.44-46.71)$ & $48.24(56.08-37.25)$ & $<0.001$ \\
\hline Males (\%) & $212(28.4)$ & $271(57.8)$ & $133(39.5)$ & $<0.001$ \\
\hline Hypertension (\%) & $307(41.1)$ & $219(46.7)$ & $103(30.6)$ & $<0.001$ \\
\hline Diabetes (\%) & 79 (10.6) & $65(13.9)$ & $34(10.1)$ & 0.145 \\
\hline Dyslipidemia (\%) & $214(28.6)$ & $177(37.7)$ & $82(24.3)$ & $<0.001$ \\
\hline Obesity (\%) & $161(21.6)$ & $114(24.3)$ & $62(18.4)$ & 0.124 \\
\hline Antihypertensive drugs (\%) & $223(29.9)$ & $162(34.5)$ & $66(19.6)$ & $<0.001$ \\
\hline Lipid-lowering drugs (\%) & $126(16.9)$ & $122(26.0)$ & $48(14.2)$ & $<0.001$ \\
\hline Antidiabetic drugs (\%) & $52(7.0)$ & $46(9.8)$ & $25(7.4)$ & 0.187 \\
\hline Office SBP $(\mathrm{mmHg})^{*} ¥$ & $123.75(134.63-113.50)$ & $125.50(138.00-114.50)$ & $121.25(131.38-109.13)$ & $<0.001$ \\
\hline Office DBP (mmHg) & $76.50(83.50-70.50)$ & $77.00(83.38-70.00)$ & $75.50(82.50-70.00)$ & 0.377 \\
\hline Office heart rate $(\mathrm{bpm})^{*} ¥ \#$ & $71.50(78.50-64.50)$ & $69.50(76.50-61.13)$ & $75.00(82.63-67.00)$ & $<0.001$ \\
\hline Central SBP $(\mathrm{mmHg})^{*} ¥$ & $124(135-114)$ & $125(137-115)$ & $121(132-110)$ & 0.002 \\
\hline Central DBP $(\mathrm{mmHg})$ & $76(83-70)$ & $77(84-70)$ & $75(82-68)$ & 0.188 \\
\hline BMI $\left(\mathrm{kg} / \mathrm{m}^{2}\right)^{*} ¥$ & $26.67(29.56-24.05)$ & $27.07(29.96-24.90)$ & $25.64(28.52-22.90)$ & $<0.001$ \\
\hline Waist circumference $(\mathrm{cm}) ¥ \#$ & $92(100-84)$ & $95(104-88)$ & $91.00(99-82)$ & $<0.001$ \\
\hline Total cholesterol (mg/dL) & $215.41 \pm 38.77$ & $213.36 \pm 39.10$ & $210.74 \pm 39.28$ & 0.192 \\
\hline Triglycerides $(\mathrm{mg} / \mathrm{dL})^{*}$ & $95(133-69)$ & $96(136-73)$ & $104(147-75)$ & 0.026 \\
\hline LDL-cholesterol (mg/dL) & $133.85 \pm 36.78$ & $133.18 \pm 34.89$ & $132.36 \pm 36.75$ & 0.827 \\
\hline HDL-cholesterol $(\mathrm{mg} / \mathrm{dL})^{*} \#$ & $59.00(70.00-49.00)$ & $56.00(67.00-47.00)$ & $54.00(64.75-45.00)$ & $<0.001$ \\
\hline Mean IMT $(\mathrm{mm})(\mathrm{n}=265) ¥$ & $0.68 \pm 0.10$ & $0.70 \pm 0.11$ & $0.65 \pm 0.11$ & 0.045 \\
\hline Maximum IMT $(\mathrm{mm})(\mathrm{n}=265) ¥$ & $0.83 \pm 0.12$ & $0.86 \pm 0.13$ & $0.81 \pm 0.13$ & 0.042 \\
\hline $\operatorname{PWV}(\mathrm{m} / \mathrm{sec})(\mathrm{n}=265)$ & $7.10(8.60-6.38)$ & $7.30(8.95-6.35)$ & $6.65(7.95-5.57)$ & 0.032 \\
\hline PAIx75 (\%) \#¥ & $89(101-78)$ & $86(97-75)$ & $90(103-77)$ & 0.003 \\
\hline$A B \mid \# ¥$ & $1.17 \pm 0.13$ & $1.19 \pm 0.14$ & $1.16 \pm 0.14$ & 0.005 \\
\hline
\end{tabular}

Normally distributed continuous variables are expressed as mean \pm standard deviation, while non-normally distributed variables are presented as median and 75-25th percentile. Frequency distribution was used in categorical variables.

Obesity: $B M I \geq 30 \mathrm{Kg} / \mathrm{m}^{2}$ or Waist circumference $\geq 88 \mathrm{~cm}$ in women and $\geq 102 \mathrm{~cm}$ in men. SBP: Systolic blood pressure; DBP: Diastolic blood pressure; $B M I$ : body mass index; HDL: high density lipoprotein; LDL: lowdensity lipoprotein; IMT: Intima Media Thickness; PWV: pulse wave velocity; PAlx75: Peripheral or radial augmentation index adjusted for heart rate at $75 \mathrm{bpm}, A B l$ : ankle brachial index.

*Differences between present and nonsmokers, ¥: Differences between present and former smokers, \#: Differences between former and nonsmokers.

and PWV are higher in the male participants, diabetics and patients undergoing vascular treatment. The PAIx 75 shows the highest values in females, individuals with diabetes and patients undergoing vascular treatments, while the ABI shows differences in individuals with and without diabetes.

Table 3 shows a bivariate correlation between systolic blood pressure, heart rate and body mass index with each vascular structure and functional parameter (i.e., PWV, IMT, PAIx75 and ABI) analysed. Age shows a linear relationship with PWV, IMT and PAIx75 (Figure 1).

After controlling for the effects of age, sex, systolic blood pressure, heart rate, body mass index, HDL-cholesterol, diabetes and the presence of antihypertensive, antidiabetic and lipid-lowering drugs, the multivariate analysis shows that present smokers have higher IMT values $(\mathrm{p}=0.011)$. PWV behaves likewise, although it does not reach the level of statistical significance. ABI has no modifications, and PAIx75 has higher values in current smokers than in former smokers (Figure 2). More details of the multivariate analysis are shown in Table 2 of the Additional file 2: (Table S2).

\section{Discussion}

In this paper, we present data about the relationship between smoking status and a large variety of parameters that assess vascular structure and function in a general population sample from primary care clinics. To assess vascular structure and function, parameters differ in their relationships with cardiovascular risk factors. The 
Table 2 Values of vascular structure and functional parameters according to sex and presence of diabetes, antihypertensive, antidiabetic and lipid lowering drugs

\begin{tabular}{|c|c|c|c|c|c|c|c|c|}
\hline & \multicolumn{2}{|c|}{ PWV $(n=265)$} & \multicolumn{2}{|c|}{ IMT $(n=265)$} & \multicolumn{2}{|c|}{ PAlx75 $(n=1553)$} & \multicolumn{2}{|c|}{$A B I(n=1553)$} \\
\hline & & p-value & & p-value & & p-value & & $\overline{p \text {-value }}$ \\
\hline \multicolumn{9}{|l|}{ Sex } \\
\hline Male & $7.6(6.7-9.5)$ & $<0.001$ & $0.71 \pm 0.12$ & $<0.001$ & $83(94-71)$ & $<0.001$ & $1.18 \pm 0.14$ & 0.455 \\
\hline Female & $6.8(6.0-7.9)$ & & $0.66 \pm 0.09$ & & $91(105-81)$ & & $1.17 \pm 0.13$ & \\
\hline \multicolumn{9}{|l|}{ Diabetes } \\
\hline Yes & $9.6(8.3-10.9)$ & $<0.001$ & $0.74 \pm 0.07$ & 0.007 & $93(104-92)$ & 0.001 & $1.15 \pm 0.16$ & 0.022 \\
\hline No & $7.0(6.1-8.2)$ & & $0.67 \pm 0.11$ & & $87(100-77)$ & & $1.18 \pm 0.13$ & \\
\hline \multicolumn{9}{|c|}{ Antihypertensive drugs } \\
\hline Yes & $8.3(7.3-9.8)$ & $<0.001$ & $0.74 \pm 0.10$ & $<0.001$ & $89(102-79)$ & 0.033 & $1.18 \pm 0.14$ & 0.693 \\
\hline No & $6.8(5.9-7.8)$ & & $0.66 \pm 0.10$ & & $87(100-76)$ & & $1.17 \pm 0.13$ & \\
\hline \multicolumn{9}{|c|}{ Antidiabetic drugs } \\
\hline Yes & $9.5(10.6-8.5)$ & $<0.001$ & $0.74 \pm 0.08$ & 0.048 & $93(102-83)$ & 0.004 & $1.14 \pm 0.16$ & 0.007 \\
\hline No & $7.0(8.2-6.2)$ & & $0.68 \pm 0.10$ & & $88(100-77)$ & & $1.18 \pm 0.13$ & \\
\hline \multicolumn{9}{|c|}{ Lipid lowering drugs } \\
\hline Yes & $8.1(6.9-10.8)$ & $<0.001$ & $0.74 \pm 0.09$ & $<0.001$ & $91(103-80)$ & 0.004 & $1.17 \pm 0.14$ & 0.438 \\
\hline No & $6.9(6.1-8.2)$ & & $0.67 \pm 0.10$ & & 87 (100-77) & & $1.17 \pm 0.13$ & \\
\hline
\end{tabular}

IMT: Intima Media Thickness; PWV: pulse wave velocity; PAIx75: Peripheral or radial augmentation index adjusted for heart rate at 75 bpm, $A B I$ : ankle brachial index.

$P W V$ and PAIx75 are showed in median and interquartil range and $I M T$ and $A B I$ as mean \pm Standard deviation.

p-values are for comparison of subgroups by T-Student independent groups and U Mann Whitney test.

results of this work show that IMT is the parameter that best relates to smoking status in a representative sample of adult population. After controlling for the effects of sex and other confounders, present smokers have higher mean IMT values $(\mathrm{p}=0.011)$, while the differences in PWV, PAIx75 and ABI did not reach the level of statistical significance.

The study results concerning the effects of smoking status on subclinical arterial disease align with those of other authors $[1,2]$, indicating that smoking relates to the presence of subclinical atherosclerosis in an adult

Table 3 Bivariate correlations between vascular structure and functional parameters and systolic blood pressure, heart ratio and body mass index

\begin{tabular}{lcccc}
\hline & Age & SBP & HR & BMI \\
\hline PWV $(n=265)$ & $0.558^{* *}$ & $0.623^{* *}$ & $0.169^{* *}$ & $0.353^{* *}$ \\
IMT $(n=265)$ & $0.687^{* *}$ & $0.441^{* *}$ & -0.054 & $0.250^{* *}$ \\
PAIX75 $(n=1553)$ & $0.222^{* *}$ & $0.134^{* *}$ & $0.361^{* *}$ & $0.103^{* *}$ \\
ABI $(n=1553)$ & 0.045 & $-0.063^{*}$ & -0.038 & 0.033 \\
\hline
\end{tabular}

${ }^{*} \mathrm{p}<0.05,{ }^{* *} \mathrm{p}<0.01$.

$S B P$ : Systolic blood pressure; $H R$ : heart rate; $B M I$ : body mass index; IMT: Intima

Media Thickness; PWV: pulse wave velocity; PAIx75: Peripheral or radial augmentation index adjusted for heart rate at $75 \mathrm{bpm}, A B \mathrm{l}$ : ankle brachial index. population. Some authors have reported that smoking aligned with increased inflammatory markers $[19,20]$. Other authors have shown that the polymorphism -930A/G may modify the association between smoking and IMT values, particularly among healthy young adults [21]. We found no correlation between the mean package years in present smokers with IMT. This result can be explained by the small number of present smokers for whom the IMT was analysed.

After controlling for confounders, we found no association between the presence of smoking and increased arterial stiffness. In a systematic literature review, Doonan RJ et al. [22] found that some studies found no significant difference in the arterial stiffness between non-smokers and long-term smokers; they concluded that the effect of smoking on arterial stiffness remains to be established by prospective smoking cessation trials. Rhee et al. found an association between PWV and cigarette smoking in male smokers with hypertension. Their study explored the acute effects of smoking in a sample of men with and without hypertension, while our work examined the chronic effects of smoking on a larger sample of the Spanish general population. Other differences between the study of Rhee and Kubozono $[3,4]$ and our work are the different variables used in the multiple regression models. Age and SBP [10] are among the major determinants of PWV. 


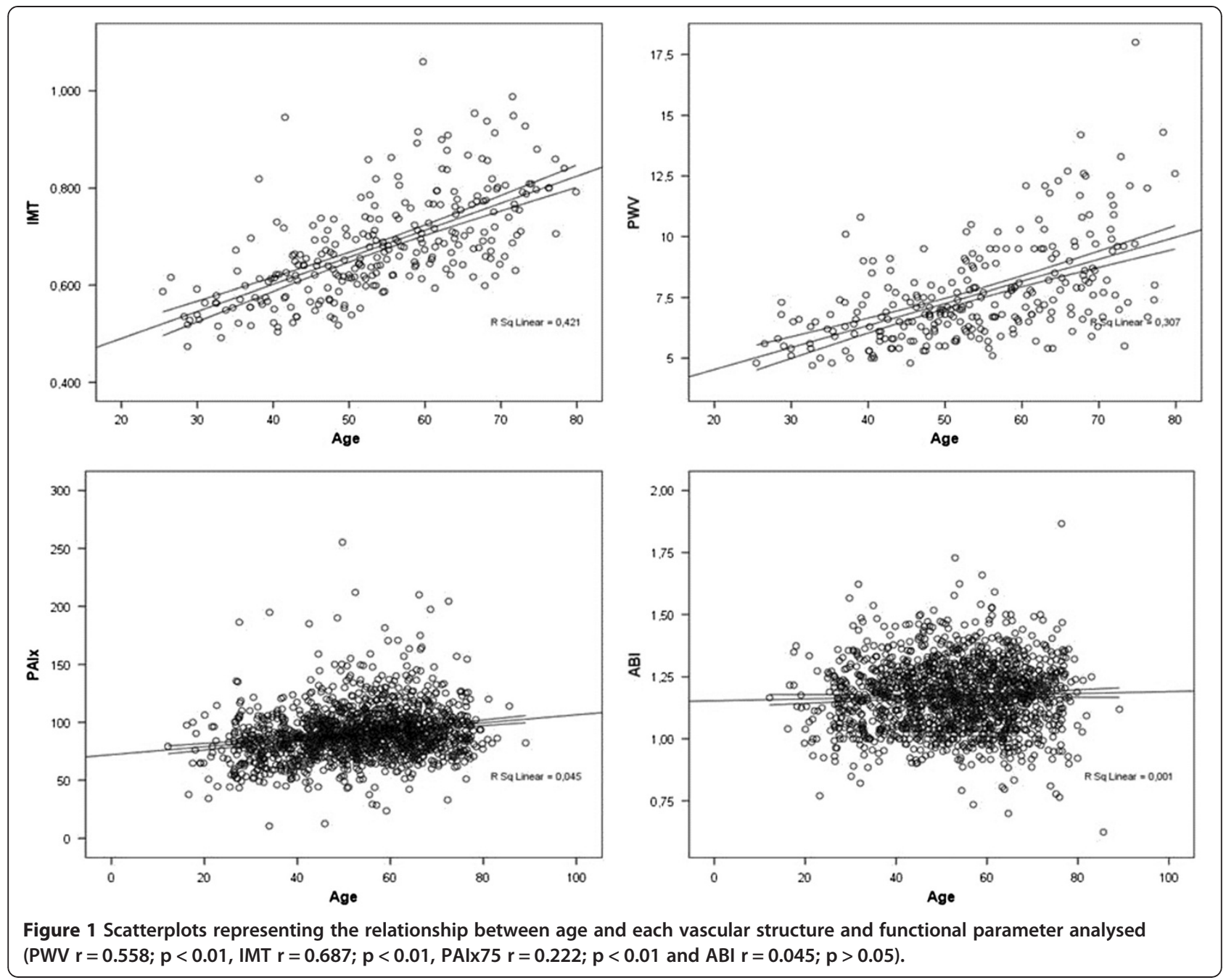

In our study, the smoker group was the youngest and had lower SBP values. Although these variables were included in the multivariate analysis model, it may not be sufficient to control the effects that they may have on the study results.

Previous studies have demonstrated an association between AIx and cardiovascular risk factors, including smoking $[6,23]$. In our work, the highest BMI corresponds to the former smokers group, which could explain the lower value of PAIx75 in this group because the augmentation index decreases when BMI increases [24]. Among the major determinants of PAIx75 are the patient age, SBP and BMI. In our study, the smoking group had the youngest participants and lower SBP and BMI levels. Although these two variables were included in the multivariate analysis, they may not sufficiently counteract the effects of other variables in the study. Furthermore, Janner JH et al. and Minami J et al. $[6,23]$ analysed the relationship of smoking with CAIx, while in our work we use the radial or peripheral augmentation index. Radial and central AIx are not interchangeable in the clinical practice, although the radial augmentation index has been established as a marker of vascular aging [25].

Present smokers have lower ABI values, similar to the results of other authors $[7,26]$. However, our results did not remain significant after adjusting for confounders. The study population of Lee YH et al. [26] was from the general population with a mean age of 65 and 70 years in subjects with and without peripheral arterial disease, respectively. The peripheral arterial disease is one of the major manifestations of generalised atherosclerotic disease, as a result of progressive atherosclerosis [27]; therefore, it is expected that individuals with longer smoking histories will have lower ABI values. The population studied in our work has a lower median age $(52.9 \pm 13$ years), with the youngest members in the smoking group. 


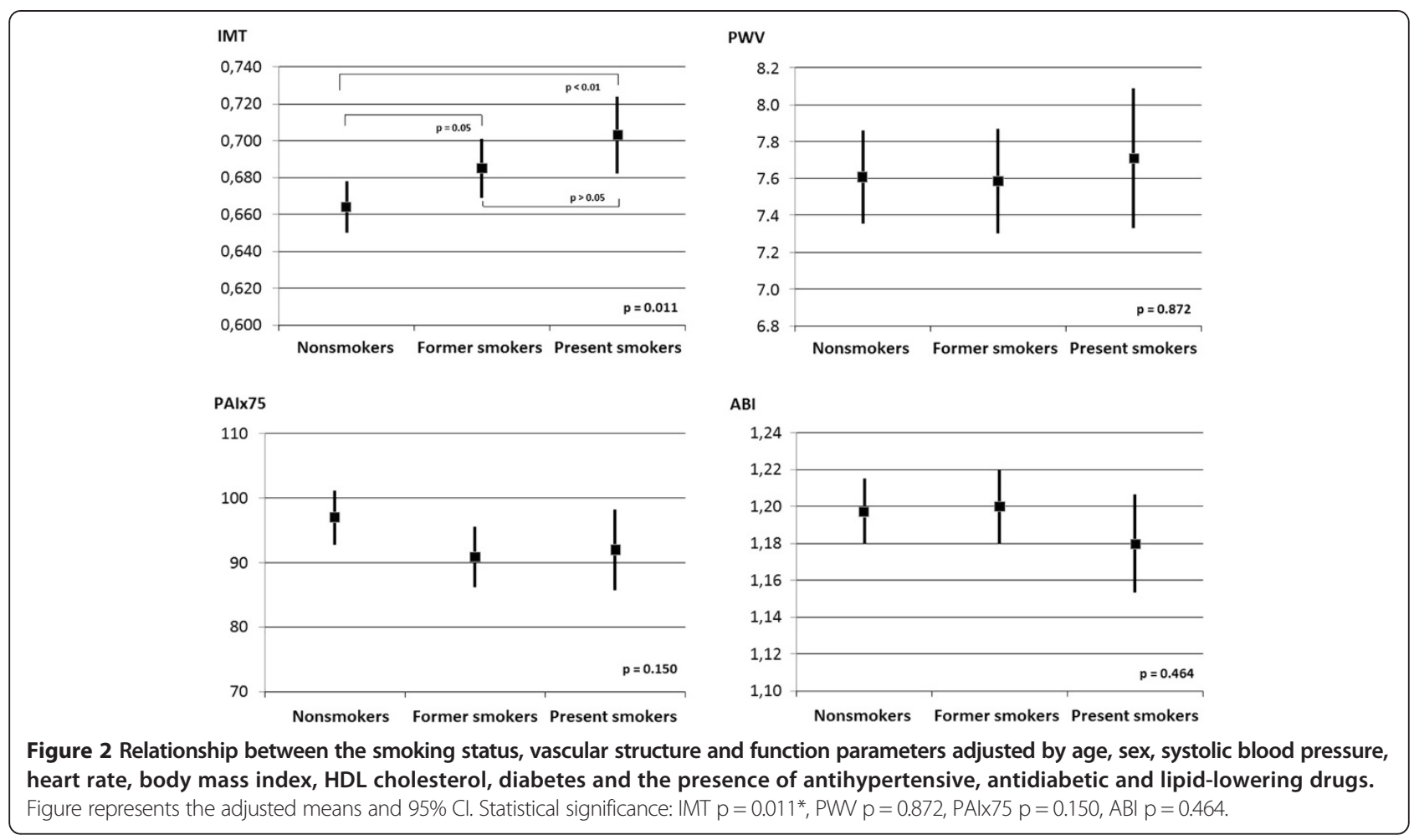

The main limitation of this study is the cross-sectional design that prevents the establishment of causal relationships between smoking and vascular structure and function. The participants of the three smoking categories differed in terms of age and the prevalence of other risk factors. This limitation is, to some extent, addressed by the statistical analysis that controls the effect of these variables in the interpretation of results. Another limitation of this study is that the smoking status was self-reported and not determined by objective measures, such as $\mathrm{CO}$ in the expired air analysis; however, such questionnaires have been used previously in other studies to explore the relationship between arterial stiffness and smoking [5]. Lastly, a full set of data (IMT and PWV) are only available in a small subset of the EVIDENT study. However, this sample has similar demographic and biological characteristics, according to smoking status, compared to the overall sample analysed.

\section{Conclusions}

Among the parameters vascular structure and function analysed, only the IMT shows association with the smoking status, after adjusting for confounders. Further studies focusing on the smoking statuses of participants are necessary to clarify the role of the chronic effects of smoking on the parameters of vascular structure and function and the effects of passive smoking exposure.

\section{Additional files}

Additional file 1: Table S1. Characteristics of patients by smoking status in the 265 subjects for whom the IMT and the PWV was assessed.

Additional file 2: Table S2. Multivariate analysis of structure and function vascular parameters with smoking status (GLM).

\section{Abbreviations}

BMI: Body mass index; PAIx75: Peripheral or radial augmentation index adjusted for heart rate at 75 bpm; ABI: Ankle brachial index; IMT: Intima-media thickness of the common carotid artery; PWW: Pulse wave velocity.

\section{Competing interests}

The author's declare that they have no competing interests.

\section{Authors' contribution}

JIR devised the study, designed the protocol, assisted with fund raising and results interpretation, prepared the draft of the manuscript and corrected the final version of the manuscript. MAG, CM, El and AM participated in the study design, results interpretation, and manuscript review. CA participated in the study design, data collection and manuscript review. MCP performed all analytical methods, results interpretation, and manuscript review. LG participated in the protocol design, fund raising, analysis of results, and final review of the manuscript. Finally, all authors reviewed and approved the final version of the manuscript.

\section{Acknowledgements}

This project was supported by Castilla y León Health Service (SAN/1778/2009), Carlos III Institute of Health of the Ministry of Health of Spain (PS09/00233, PS09/01057, PS09/01972, PS09/01376, PS09/0164, PS09/01458, RETICS RD12/ 0005/0004) and the Infosalud Foundation. 


\section{EVIDENT group members}

Coordinating centre: Luis Garcia Ortiz, Manuel A Gómez Marcos, José I Recio Rodriguez and Carmen Patino Alonso of the Primary Care Research Unit of La Alamedilla Health Centre, Salamanca, Spain.

Participating centres: La Alamedilla Health Center, Servicio de Salud de Castilla y León SACYL: Carmen Castaño Sánchez, Carmela Rodriquez Martín, Yolanda Castaño Sánchez, Cristina Agudo Conde, Emiliano Rodriguez Sánchez, Luis J Gonzalez Elena, Carmen Herrero Rodriguez, Benigna Sánchez Salgado, Angela de Cabo Laso and Jose A Maderuelo Fernández. Passeig de Sant Joan Health Centre, Servicio de Salud Catalan: Carlos Martín Cantera, Joan Canales Reina, Epifania Rodrigo de Pablo, Maria Lourdes Lasaosa Medina, Maria Jose Calvo Aponte, Amalia Rodriguez Franco, Elena Briones Carrio, Carme Martin Borras, Anna Puig Ribera and Ruben Colominas Garrido. Poble Sec Health Centre, Servicio de Salud Catalan: Juanjo Anton Alvarez, Ma Teresa Vidal Sarmiento, Ángela Viaplana Serra, Susanna Bermúdez Chillida, Aida Tanasa

Ca N'Oriac Health Centre, Servicio de Salud Catalan: Montserrat Romaguera Bosch.

Sant Roc Health Centre, Servicio de Salud Catalan: Maria Mar Domingo, Anna Girona, Nuria Curos, Francisco Javier Mezquiriz, Laura Torrent.

Cuenca III Health Centre, Servicio de Salud de Castilla-La Mancha SESCAM Alfredo Cabrejas Sánchez, María Teresa Pérez Rodríguez, María Luz García García, Jorge Lema Bartolomé and Fernando Salcedo Aguilar. Casa de Barco Health Centre, Servicio de Salud de Castilla y León SACYL: Carmen Fernandez Alonso, Amparo Gómez Arranz, Elisa Ibáñez Jalón, Aventina de la Cal de la Fuente, Laura Muñoz Beneitez, Natalia Gutiérrez, Ruperto Sanz Cantalapiedra, Luis M Quintero Gonzalez, Sara de Francisco Velasco, Miguel Angel Diez Garcia, Eva Sierra Quintana and Maria Cáceres. Torre Ramona Health Centre, Servicio de Salud de Aragon: Natividad González Viejo, José Felix Magdalena Belio, Luis Otegui Ilarduya, Francisco Javier Rubio Galán, Amor Melguizo Bejar, Cristina Inés Sauras Yera, Ma Jesus Gil Train, Marta Iribarne Ferrer and Miguel Angel Lafuente Ripolles. Primary Care Research Unit of Bizkaia, Basque Health Service-Osakidetza: Gonzalo Grandes, Alvaro Sanchez, Nahia Guenaga, Veronica Arce, Maria SoledadArietaleanizbealoa, Eguskiñe Iturregui San Nicolás, Rosa Amaia Martín Santidrián and Ana Zuazagoitia.

\section{Author details}

'La Alamedilla Health Centre, Castilla y León Health Service-SACYL, redIAPP, IBSAL, Salamanca, Spain. ${ }^{2}$ Statistics Department, University of Salamanca, Salamanca, Spain. ${ }^{3}$ Passeig de Sant Joan Health Centre, Catalan Health Service, Barcelona, Spain. ${ }^{4}$ Casa de Barco Health Centre, Castilla y León Health Service-SACYL, Valladolid, Spain. ${ }^{5}$ Torre Ramona Health Centre, Aragón Health Service, Zaragoza, Spain

Received: 12 July 2013 Accepted: 26 November 2013 Published: 1 December 2013

\section{References}

1. Howard G, Wagenknecht LE, Burke GL, Diez-Roux A, Evans GW, McGovern P, Nieto FJ, Tell GS: Cigarette smoking and progression of atherosclerosis: The Atherosclerosis Risk in Communities (ARIC) Study. JAMA 1998, 279(2):119-124

2. Jockel KH, Lehmann N, Jaeger BR, Moebus S, Mohlenkamp S, Schmermund A, Dragano N, Stang A, Gronemeyer D, Seibel R, et al: Smoking cessation and subclinical atherosclerosis-results from the Heinz Nixdorf Recall Study. Atherosclerosis 2009, 203(1):221-227.

3. Kubozono T, Miyata M, Ueyama K, Hamasaki S, Kusano K, Kubozono O, Tei C: Acute and chronic effects of smoking on arterial stiffness. Circ J 2011, 75(3):698-702

4. Rhee MY, Na SH, Kim YK, Lee MM, Kim HY: Acute effects of cigarette smoking on arterial stiffness and blood pressure in male smokers with hypertension. Am J Hypertens 2007, 20(6):637-641.

5. Mahmud A, Feely J: Effect of smoking on arterial stiffness and pulse pressure amplification. Hypertension 2003, 41(1):183-187.

6. Janner JH, Godtfredsen NS, Ladelund S, Vestbo J, Prescott E: The association between aortic augmentation index and cardiovascular risk factors in a large unselected population. J Hum Hypertens 2012, 26(8):476-484.

7. Cui R, Iso H, Yamagishi K, Tanigawa T, Imano H, Ohira T, Kitamura A, Sato S, Shimamoto T: Relationship of smoking and smoking cessation with ankle-to-arm blood pressure index in elderly Japanese men. Eur J Cardiovasc Prev Rehabil 2006, 13(2):243-248.
8. Hennrikus D, Joseph AM, Lando HA, Duval S, Ukestad L, Kodl M, Hirsch AT: Effectiveness of a smoking cessation program for peripheral artery disease patients: a randomized controlled trial. J Am Coll Cardiol 2010 56(25):2105-2112.

9. Gomez-Marcos MA, Gonzalez-Elena $\sqcup$, Recio-Rodriguez II, Rodriguez-Sanchez E, Magallon-Botaya R, Munoz-Moreno MF, Patino-Alonso MC, Garcia-Ortiz L: Cardiovascular risk assessment in hypertensive patients with tests recommended by the European guidelines on hypertension. Eur J Prev Cardiol 2012, 19(3):515-522.

10. Determinants of pulse wave velocity in healthy people and in the presence of cardiovascular risk factors: 'establishing normal and reference values'. Eur Heart J 2010, 31(19):2338-2350.

11. Recio-Rodriguez Jl, Gomez-Marcos MA, Patino-Alonso MC, Agudo-Conde C, Rodriguez-Sanchez E, Garcia-Ortiz L: Abdominal obesity vs general obesity for identifying arterial stiffness, subclinical atherosclerosis and wave reflection in healthy, diabetics and hypertensive. BMC Cardiovasc Disord 2012, 12:3

12. Garcia-Ortiz L, Garcia-Garcia A, Ramos-Delgado E, Patino-Alonso MC, Recio-Rodriquez Jl, Rodriquez-Sanchez E, Gomez-Marcos MA: Relationships of night/day heart rate ratio with carotid intima media thickness and markers of arterial stiffness. Atherosclerosis 2011, 217(2):420-426.

13. Lee HY, Oh BH: Aging and arterial stiffness. Circ J 2010, 74(11):2257-2262.

14. Garcia-Ortiz L, Recio-Rodriguez JI, Puig-Ribera A, Lema-Bartolome J, Ibanez-Jalon E, Gonzalez-Viejo N, Guenaga-Saenz N, Agudo-Conde C, Patino-Alonso MC, Gomez-Marcos MA: Blood pressure circadian pattern and physical exercise assessment by accelerometer and 7-day physical activity recall scale. Am J Hypertens 2013. Epub ahead of print.

15. Touboul PJ, Hennerici MG, Meairs S, Adams H, Amarenco P, Bornstein N, Csiba L, Desvarieux M, Ebrahim S, Fatar M: Mannheim carotid intima-media thickness consensus (2004-2006). An update on behalf of the Advisory Board of the 3rd and 4th Watching the Risk Symposium, 13th and 15th European Stroke Conferences, Mannheim, Germany, 2004, and Brussels, Belgium, 2006. Cerebrovasc Dis 2007, 23(1):75-80.

16. Van Bortel LM, Laurent S, Boutouyrie P, Chowienczyk P, Cruickshank JK, De Backer T, Filipovsky J, Huybrechts S, Mattace-Raso FU, Protogerou AD, et al: Expert consensus document on the measurement of aortic stiffness in daily practice using carotid-femoral pulse wave velocity. J Hypertens 2012, 30(3):445-448.

17. Hirsch AT, Haskal ZJ, Hertzer NR, Bakal CW, Creager MA, Halperin JL, Hiratzka LF, Murphy WR, Olin JW, Puschett JB, et al: ACC/AHA Guidelines for the Management of Patients with Peripheral Arterial Disease (lower extremity, renal, mesenteric, and abdominal aortic): a collaborative report from the American Associations for Vascular Surgery/Society for Vascular Surgery, Society for Cardiovascular Angiography and Interventions, Society for Vascular Medicine and Biology, Society of Interventional Radiology, and the ACC/AHA Task Force on Practice Guidelines (writing committee to develop guidelines for the management of patients with peripheral arterial disease)-summary of recommendation. J Vasc Interv Radiol 2006, 17(9):1383-1397. quiz 1398

18. Garcia-Ortiz L, Recio-Rodriguez Jl, Martin-Cantera C, Cabrejas-Sanchez A, Gomez-Arranz A, Gonzalez-Viejo N, Iturregui-San Nicolas E, Patino-Alonso MC, Gomez-Marcos MA: Physical exercise, fitness and dietary pattern and their relationship with circadian blood pressure pattern, augmentation index and endothelial dysfunction biological markers: EVIDENT study protocol. BMC Public Health 2010, 10:233.

19. Casula M, Tragni E, Zambon A, Filippi A, Brignoli O, Cricelli C, Poli A, Catapano AL: C-reactive protein distribution and correlation with traditional cardiovascular risk factors in the Italian population. Eur J Intern Med 2013, 24(2):161-166.

20. Asthana A, Johnson HM, Piper ME, Fiore MC, Baker TB, Stein JH: Effects of smoking intensity and cessation on inflammatory markers in a large cohort of active smokers. Am Heart J 2010, 160(3):458-463.

21. Fan M, Raitakari OT, Kahonen M, Juonala M, Hutri-Kahonen N, Porsti I, Viikari J, Lehtimaki $\mathrm{T}$ : The association between cigarette smoking and carotid intima-media thickness is influenced by the -930A/G CYBA gene polymorphism: the Cardiovascular Risk in Young Finns Study. Am J Hypertens 2009, 22(3):281-287.

22. Doonan RJ, Hausvater A, Scallan C, Mikhailidis DP, Pilote L, Daskalopoulou SS: The effect of smoking on arterial stiffness. Hypertens Res 2010, 33(5):398-410.

23. Minami J, Ishimitsu T, Ohrui M, Matsuoka H: Association of smoking with aortic wave reflection and central systolic pressure and metabolic 
syndrome in normotensive Japanese men. Am J Hypertens 2009, 22(6):617-623.

24. Maple-Brown L, Piers LS, O'Rourke MF, Celermajer DS, O'Dea K: Central obesity is associated with reduced peripheral wave reflection in indigenous Australians irrespective of diabetes status. J Hypertens 2005, 23(7):1403-1407.

25. Heffernan KS, Patvardhan EA, Kapur NK, Karas RH, Kuvin JT: Peripheral augmentation index as a biomarker of vascular aging: an invasive hemodynamics approach. Eur J Appl Physiol 2012, 112(8):2871-2879.

26. Lee YH, Shin MH, Kweon SS, Choi JS, Rhee JA, Ahn HR, Yun WJ, Ryu SY, Kim $\mathrm{BH}, \mathrm{Nam} \mathrm{HS}$, et al: Cumulative smoking exposure, duration of smoking cessation, and peripheral arterial disease in middle-aged and older Korean men. BMC Public Health 2011, 11:94.

27. Newman AB, Siscovick DS, Manolio TA, Polak J, Fried LP, Borhani NO, Wolfson SK: Ankle-arm index as a marker of atherosclerosis in the Cardiovascular Health Study. Cardiovascular Heart Study (CHS) Collaborative Research Group. Circulation 1993, 88(3):837-845.

doi:10.1186/1471-2261-13-109

Cite this article as: Recio-Rodriguez et al:: Association between smoking status and the parameters of vascular structure and function in adults: results from the EVIDENT study. BMC Cardiovascular Disorders 2013 13:109.

\section{Submit your next manuscript to BioMed Central and take full advantage of:}

- Convenient online submission

- Thorough peer review

- No space constraints or color figure charges

- Immediate publication on acceptance

- Inclusion in PubMed, CAS, Scopus and Google Scholar

- Research which is freely available for redistribution 